\title{
Transient feelings of compulsion caused by hemispheric lesions: three cases
}

\author{
CHRISTOPHER D WARD \\ From the University Rehabilitation Unit, Southampton General Hospital, Southampton, UK
}

SUMMARY There was strong evidence of a neurological explanation for transient feelings of compulsion reported by three patients. In at least two cases the mechanism was epileptic. The frontal lobe was implicated in all three. A feeling of compulsion, divorced from action, has rarely if ever been reported in epilepsy or other neurological disorders.

As defined by Fish, ${ }^{1}$ an obsession is a thought which is "experienced as occurring against the patient's will ... If the obsession leads to an act, then it is called a compulsion". Neither obsessions nor compulsions are commonly associated with neurological disorders. Non-specific obsessional thoughts and sometimes a vague sense of compulsion can accompany oculogyria caused by encephalitis ${ }^{2}$ or by drugs, ${ }^{3}$ and similar phenomena are associated with tics in post-encephalitic states $^{2}$ and in Gilles de la Tourette syndrome. ${ }^{4}$ In these conditions the ensuing involuntary movement generally overcomes internal resistance and seems to be the primary phenomenon, whereas Aubrey Lewis suggested that in obsession-compulsion disorder the reverse is true. ${ }^{5}$ Three patients with no previous psychiatric history described involuntary urges which could be termed obsessions. Although the obsessions represented specific actions no movement ensued. The term "feeling of compulsion" rather than compulsion is required to describe them. A feeling of compulsion not issuing in action should technically be termed an "obsession" but no suitable verb can be formed from this word, and for the sake of clarity the term "feeling of compulsion" is preferred in this paper. The feelings of compulsion were clearly associated with hemispheric lesions. The fact that no movement occurred indicates that the feelings of compulsion were primary neurological events rather than epiphenomena.

Address for reprint requests: Dr C D Ward, University Rehabilitation Unit, Southampton General Hospital, SO9 4XY, UK.

Received 24 March 1987 and in revised form 31 July 1987. Accepted 14 August 1987

\section{Case reports}

All three patients were right-handed. None had a previous history of neurological or psychiatric disorder.

Case 1 A woman aged 59 years was walking in the street with the traffic on her left. Suddenly she experienced a strong urge to walk to the left. At the same time her head and neck rotated involuntarily towards the right. The attack lasted a few seconds and she was able to continue walking. She explained afterwards that she resisted the urge to walk to the left by an effort of will; had she not done so she would have strayed off the curb. She had no further similar episodes. When she was first examined there were no neurological signs. A few weeks later she was admitted following the development of a mild left hemiparesis. Electroencephalography (EEG) showed a focal abnormality in the right frontal region. Computed tomographic (CT) scan revealed a frontoparietal tumour, and biopsy confirmed that it was a glioblastoma.

Case 2 A man aged 43 years presented with a 2 month history of about eight brief episodes in which he experienced a strong urge to shake his right arm. Sometimes this was accompanied by an urge to shout. He was reading during one attack and reported transient blurring of the print. On another occasion, while driving, the attack was associated with a slight feeling of spatial disorientation but there were no other neurological events and in particular he never moved his arm or shouted. He was never speaking at the time of an attack so that language function could not be assessed. In the 2 days before admission he had episodes of transient speech arrest and of transient weakness of the right arm. On examination he had very mild expressive dysphasia, papilloedema, and a mild right hemiparesis. EEG abnormalities were maximal in the left frontal and temporal areas, and CT scan showed a left frontal mass which proved on biopsy to be a glioblastoma.

Case 3 A woman aged 62 years had an episode of expressive dysphasia, witnessed by a friend, lasting about 5 
minutes. She subsequently denied that she had had any comprehension difficulty. In the next 6 weeks she had three or four episodes, each lasting a few seconds, in which she felt the urge to shake her right arm. She always overcame the urge successfully. There were no associated symptoms: she was able to continue walking during one such episode; since she was alone on each occasion there was no information about her language function. There were no neurological signs when examined 6 weeks after the first episode, and she was normotensive. She remained well subsequently. Routine investigations including full blood count and electrocardiogram were normal. An EEG showed some abnormality over the left temporal area but no definite epileptic activity. A CT scan showed small, questionable lucencies consistent with lacunar infarcts in the right superior cerebellar peduncle and the left basal ganglia.

\section{Discussion}

In each of these cases there was a transient feeling of compulsion, combined with an inner resistance, while insight was fully preserved. These are the three features of obsession-compulsion disorder. ${ }^{5}$ It is likely (although not certain) that consciousness was preserved and that subsequent memory of the episode was complete. None of the cases at any time succumbed to the urge to make a movement. The feeling of compulsion was to act in a certain way (defining action in this context as a sequence of movements which, if under voluntary control, would seem purposeful: walking off a curb to the left; or raising the right arm with or without simultaneously shouting). There is little room for doubt that in each case the basis for the phenomenon was a lesion in a cerebral hemisphere. In Case 1 and in Case 2 there was strong evidence that the mechanism was an epileptic focus. The brief and inconsequential nature of the feelings of compulsion was consistent with that of other ictal events such as hallucinations. In Cases 1 and 2 a proven glioma involved a frontal lobe, although the relevant epileptic focus could have been outside the frontal lobe since the tumours were large and associated with oedema. In Case 2 the clinical features of other partial seizures (speech arrest and arm weakness) provided further evidence that the epileptic focus was frontal. Case 3 had an episode of transient dysphasia which could readily have been ascribed to transient cerebral ischaemia involving the left frontal lobe. Accordingly, the series of feelings of compulsion to raise the right arm, following shortly on the dysphasic episode, most probably shared a similar basis. The mechanism remains uncertain. There was no strong EEG evidence to suggest epilepsy and the CT findings were of dubious significance.

A sense of compulsion as a purely intellectual aberration entirely divorced from involuntary movement has not, so far as I know, been reported in epilepsy, movement disorders or other neurological conditions known to affect thinking or behaviour. Oculogyria ${ }^{2} 3$ and $\operatorname{tics}^{24}$ may be associated with a premonitory sense of compulsion and tics may be temporarily suppressed by effort of will. In general, the movements occur despite inner resistance. The feelings are never more than partially divorced from the movements. Patients with Gilles de la Tourette syndrome experience an indefinite sense of urgency which is relieved by allowing the tic to be expressed. Whether the sense of urgency takes the form of a specific idea, a feeling of compulsion to act in a certain way is doubtful. Obsessional thinking may accompany oculogyria and tics: its content is not directly related to the nature of the movements but may take the form of meaningless ruminations. ${ }^{5}$

Forced thinking is a rare but recognised component of complex partial seizures ${ }^{6}$ but has never been described as a feeling of compulsion to act. Many epileptics claim that an attack may be averted by voluntary effort but the manoeuvres are learned in response to a previous history of seizures. ${ }^{7}$ Compulsive behaviour, especially hypergraphia ${ }^{8}$ is an interictal feature in some patients with complex partial seizures, but is not an ictal phenomenon. Automatisms are carried out in a state of reduced consciousness with no post-ictal recollections, ${ }^{9}$ and bear little resemblance to compulsions. Inter-ictal impulsive behaviour is by definition unpremeditated. The lesions responsible for the transient feelings of compulsion described here probably involved the frontal lobe. Complex partial seizures (CPS) of frontal lobe origin are not readily distinguishable from temporal lobe CPS and compulsive phenomena have not been described. ${ }^{10}$ Forced thinking has been attributed to mainly posterior frontal lobe lesions. The four cases of epileptic forced thinking cited by Penfield and Jasper ${ }^{6}$ all had frontal foci, and Mulder stated that forced thinking was associated with posterior frontal lobe lesions. ${ }^{11}$

The interpretation of subjective disorders associated with epilepsy requires great caution. When a compelled action has occurred in the past and recurs following the feeling of compulsion, several explanations are available for the feeling and also for the manoeuvres which are claimed to overcome it. The sense of compulsion might be merely illusory. There could be a close analogy with the illusion of precognition which frequently accompanies déjà vu phenomena; post-hoc rationalisation could result in a false claim of compulsion; or a passive premonition could be based on a learned association between a warning sensation and the usual outcome: for example when nausea precedes vomiting, when there is an urge to micturate, or when a migraine attack or seizure is heralded by a familiar aura. The three cases described here experienced a sense of compulsion without prior or subsequent action. The feeling of compulsion could not have been illusory or post-hoc in the above sense, and could not have been a nonspecific sensation which habitually resulted in the 
stated action. We can therefore accept the patients' claim that the compulsion was spontaneous and comprised a specific idea, to act in a specific way.

Where did the idea come from? It seems likely that the feeling of compulsion arose from a cortical area closely related to that from which the compelled action would have originated had it occurred. In Case 1 the urge to walk to the left represented an action involving the affected right frontal lobe just as in Cases 2 and 3 the compelled actions (raising the right arm and in one case shouting) involved the affected left frontal lobe.

The principal value of these observations lies in the demonstration that a cerebral disorder can mimic a clinical syndrome which has generally been regarded as purely psychological in nature. Schilder drew attention to the parallels between obsessioncompulsion disorder as a psychiatric syndrome and phenomena such as compulsive tics and ruminations which were observed following encephalitis lethargica. ${ }^{212}$ Lewis $^{5}$ claimed that in post-encephalitic patients the involuntary movement was the "primary happening" for the post-encephalitic since the movement itself usually occurred despite feelings of inner resistance, and this would be true of all the neurological compulsive phenomena reviewed above. Lewis also observed that the obsessive thinking prior to such movements was not "a concrete image or idea" of the ensuing movement. Lewis's distinctions do not, however, apply to the cases described here. In the absence of any prior or subsequent movement, the feeling of compulsion they experienced must have been primary in Lewis's sense, and it also conformed to the other proposed criterion for the psychiatric disorder in being a "concrete image or idea" of a specific action. Psychiatric compulsions (albeit ostensibly "primary") may be products of a complex pattern of unconscious thought and inner resistance to them could be interpreted as conscious rejection of unconscious products. This process, if it occurs, may evidently be reproduced when a similarly alien idea-an epileptogenic feeling of compulsion-becomes conscious.

It can safely be concluded that accepted criteria for distinguishing psychogenic compulsions from neurological disorders are not reliable but the suggestion that obsession-compulsion disorder is itself generally caused by a focal cerebral disturbance seems farfetched. An important distinction can be drawn between mere bodily movement (for example, the raising of an arm) and its more general significance (for example reaching or waving). Many psychiatric obsessions are in the second category. The present cases suggest that a focal hemispheric lesion might result in representation of movement of a specific part of the body as a feeling of compulsion. It is less easy to see how a compulsion characterised by a certain general purpose, say hand-washing, could be under focal control. More probably, a cerebral disorder might increase the likelihood of a wide variety of obsessions and compulsions.

Epileptic symptoms often appear to reflect normal cerebral function. Since the feelings of compulsion described here concerned specific, cortically localised actions, it is possible to speculate that there was a disorder in some process normally preceding voluntary movement and presumably involving the frontal lobe. The mental representation of specific movements prior to their execution is a frontal lobe function according to Luria. ${ }^{13}$ There are grounds for supposing that the frontal lobes have a role in "policing" behaviour, preventing impulsive actions and selecting actions which are optimal for prevailing goals. ${ }^{14}$ A sense of compulsion might perhaps have arisen if a specific action was granted spurious subjective legitimacy by an epileptic discharge in a frontal lobe. The mechanisms for judging overall coherence of behaviour must have been intact, however, since internal resistance was maintained and action inhibited.

I am grateful to Professor WB Matthews for permis sion to report Cases 2 and 3.

\section{References}

1 Hamilton M. Fish's Outline of Psychiatry. Bristo Wright, 1978:42.

2 Ward CD. Encephalitis lethargica and the development of neuropsychiatry. Psychiatr Clin $N A m^{+}$ 1986;9:215-24.

3 Bumpass ER, Knoll JL. Emotional factors in oculogyric crisis. J Nerv Ment Dis 1982;170:366-70.

4 Lees AJ. Tics and related disorders. Edinburgh: Churchill Livingstone, 1985.

5 Lewis A. Problems of obsessional illness. Proc $R$ Soc Med 1936;29:325-36.

6 Penfield W, Jasper H. Epilepsy and the Functional Anatomy of the Brain. London: Churchill, 1954:468-9.

7 Pritchard PB, Holmstrom VL, Giacinto J. Selfabatement of complex partial seizures. Ann Neurol 1985; 18:265-7.

8 Waxman SG, Geschwind N. Hypergraphia in temporal lobe epilepsy. Neurology 1974;24:629-36.

9 Daly DD. Ictal manifestations of complex partial seizures. Adv Neurol 1975;11:57-82.

10 Williamson PD, Spencer DD, Spencer SS, Novelly RA, Mattson RH. Complex partial seizures of frontal lobe origin. Ann Neurol 1985;18:497-504.

11 Mulder DW. Paroxysmal psychiatric symptoms observed in epilepsy. Staff Meetings of the Mayo Clinic 1953;28:31-5.

12 Schilder $P$. The organic background of obsessions and compulsions. Am J Psychiatry 1938;94:1397-1415.

13 Luria AR. The Working Brain. London: Allen Lane, The Penguin Press, 1973.

14 Duncan J. Disorganization of behaviour after frontal damage. Cog Neuropsychol 1986;3:271-90. 